\title{
Society for Pediatric Research Presidential Address 1993: Development of the Academic Pediatrician
}

\author{
GEORGE LISTER \\ Department of Pediatrics, Yale University School of Medicine. New Haven. Connecticut 06510
}

Friends, colleagues, and my dear family, I have been granted the privilege of standing before you to share my thoughts on a topic of interest to me, and hopefully to you also. I have chosen an issue that affects all of us-the students and residents in the audience, the postdoctoral fellows, junior faculty, and the more senior faculty who serve as section chiefs, directors of training programs, and of course, the few chairmen who have the luxury of attending a meeting with someone other than the hospital director. I have long been interested in the development and metamorphosis of the young physician into the academic pediatrician. This process does not occur passively. Rather, it requires nourishment, specialized environments, reinforcement, and time, just as is needed with the proper rearing of our children or the culturing of cells. This process of nurturing is vital to the health of pediatrics as a science-based discipline, and should be of central concern to all of us. Without proper attention to career development, the pediatric physician-scientist will fail to thrive, a concern expressed by many of my predecessors in their address to this Society $(1,2)$. It is for this reason that I wish to focus my comments on the path of career development-the goals, the obstacles, the signposts, and, hopefully, some useful suggestions on how to guide the process.

While meeting in Washington, it takes little to conjure the air of pessimism regarding the fate of academic medicine, but I would like to start on a positive note and, for a moment, speak specifically to those of you in training. You have heard the voice of the naysayers who have reminded us of the tedious and uncertain process of obtaining grant support: the pressure to publish; the constant exposure of our ideas to criticism; the difficulties inherent in balancing the consuming demands of research, clinical, and teaching responsibilities with the fulfilling needs of having a family and friends. Yes, the times are tough. Yes, the career is challenging and exhausting. However, I can think of few other careers where you are accorded so much freedom to chart your own destiny. You will have the opportunity to blend a variety of components in a mixture of your choice. You will receive personal satisfaction and peer recognition from your creative endeavors. You may even feel useful. Your challenge is to create a career that excites you and is designed to highlight your strengths and interests, rather than fit your talents into someone else's job description. I think we are very fortunate indeed.

We have also heard the echo through the halls that funds are limited, but this plight is not restricted to medicine or to current times. Engineers, lawyers, and even stock brokers are out of work. We at least have a modicum of security in our job. And, in terms of research funding, our struggle for support is by no means new. As shown by this summary statement for a grant application from Christopher Columbus to Queen Isabella and King Ferdinand, the times have always been tough and funds limited. I shall only read a few of the comments from the summary statement, but I am sure you can comprehend the impact: "The entire basis of the proposal rests on the thesis, as yet unproven, that the world is round. Disapproval is recommended based on the lack of scientific merit. The aims. . are certainly laudable, but the rather naive approach reflects a serious lack of academic research experience and training by the PI."

Columbus, who was finally funded by Isabella, may have even had a difficult time today because of the lack of rigor in his presentation. Despite the intended humor here, we should take seriously the nature of the criticism that calls for more experience and training, which brings me to the points I wish to raise today.

\section{GOALS}

I believe there are several goals for the physician in postdoctoral training. The first is to identify areas for clinical and scholarly pursuit that are captivating and fulfilling-those that will sustain interest even when your research and writing are not going well. This goal is the vision of your career. You may have to forage for a long time to find areas to sustain you, but this time is well spent.

You will certainly be influenced in your choice by those whom you admire and like, but you cannot choose an endeavor just to please those important people. Based on your experience during medical school and residency, you may know what clinical discipline is of prime interest. It is less likely that you will have had sufficient investigative experience even to know whether you enjoy research, but you should make every effort to find out during this phase of your education. It is not essential that your research interests be immediately applicable to your clinical interests. Achievement in each area will provide its own satisfaction and enhance the other endeavor.

You may also come to the realization that the "attractions" of an academic career do not motivate you, a valid and important decision that is best made early.

The next goal is to acquire the skills, both cognitive and technical, necessary to pursue your chosen endeavors. This as the basis for the curriculum devised to reach your vision. The cognitive skills take much time to develop and there is no ready means to short circuit this vital process. Reading a review article is no substitute for comprehending original sources, and comprehension, of necessity, requires a struggle. These struggles will serve as the opportunity for you to enrich your and our understanding of a topic. You must also develop skills to facilitate communication, to present your ideas to students, to colleagues. and to critics in written and in oral form. And, finally, depending on your area of interest, you will need to develop technical skills. which may also require a considerable time commitment. The opportunities for acquisition of these essential ingredients must be inherent components of any program for postdoctoral education of physicians.

A final goal is to find interesting questions and formulate testable hypotheses to pursue. This, too, cannot be fulfilled in a brief period of time. Questions arise from immersion in a field, intense review of prior studies, and frequent discussion and 


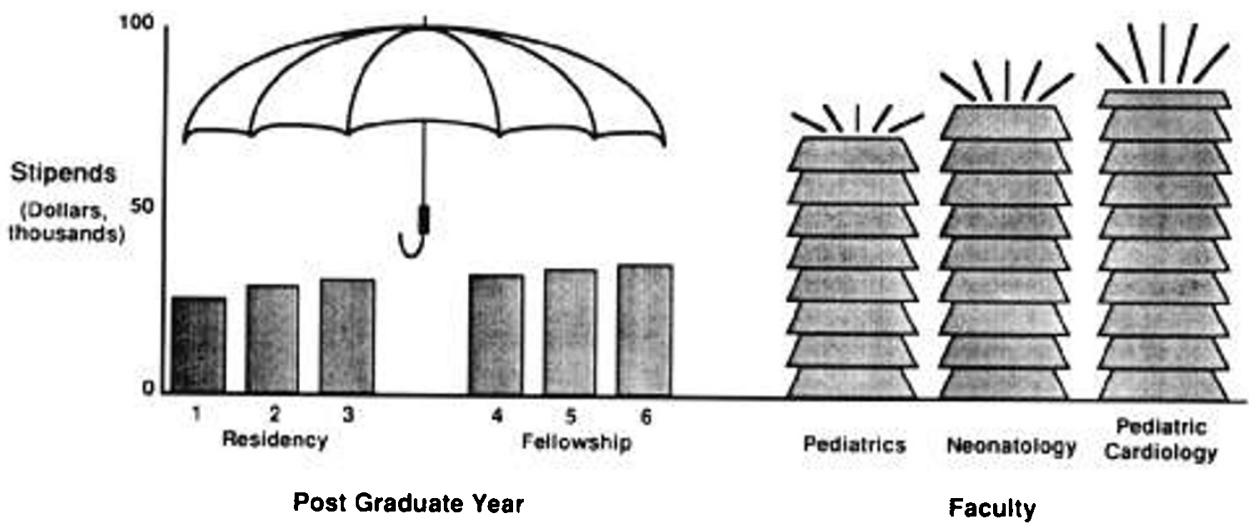

Fig. 1. Stipends during the typical progression from residency to assistant professor in pediatrics. The umbrella represents the time for protected training. Data for residency are from reference 3. Data for fellowship are based on current stipends from the National Institutes of Health for National Research Service Awards at the appropriate postgraduate level. Data for faculty are from reference 4; these values are for compensation for faculty with an M.D. degree receiving only a base compensation, 1992-1993.

\section{CLINICAL SKILLS}

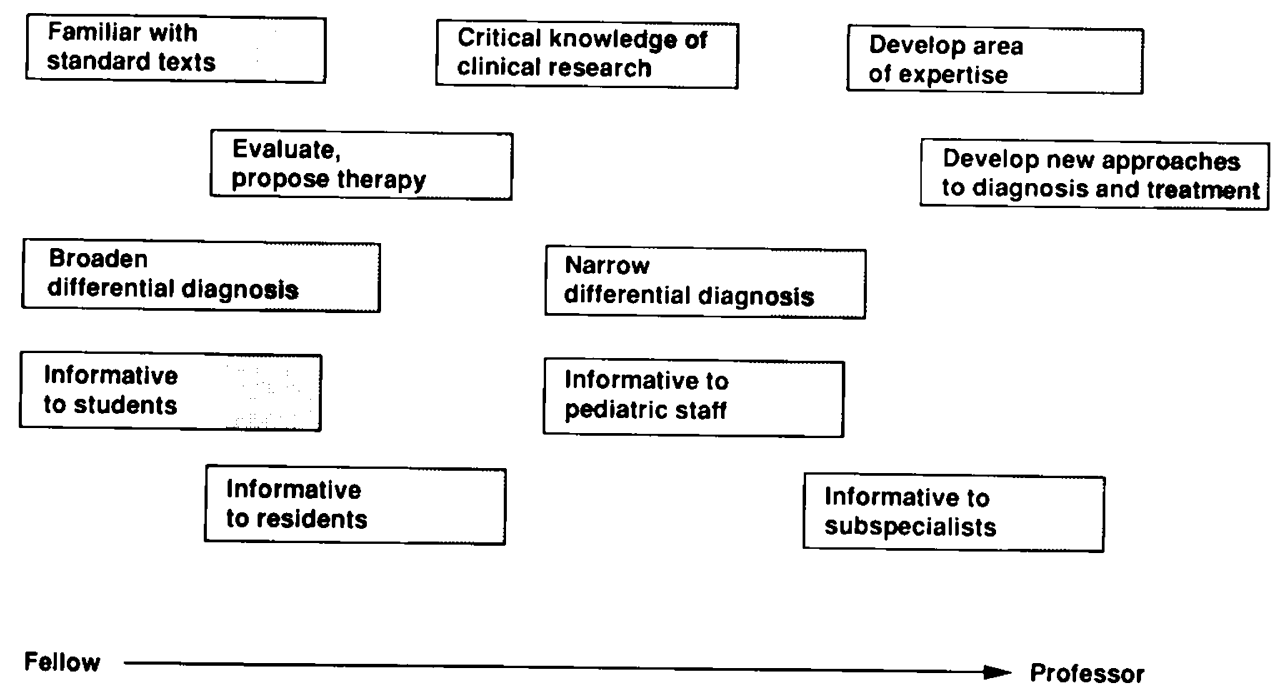

Fig. 2. Refinement of clinical skills during the development from postdoctoral fellow to professor.

arguments with colleagues and oneself. While raw questions may arise frequently, well-constructed hypotheses require considerable refinement before they are in a shape that can be addressed rigorously.

An essential irony here is that we as training directors often expect a fellow to develop a sophisticated hypothesis as the basis for his or her first project. The problem with this approach is that the fellow does not have the background to accomplish the task. Rather, we should expect that the initial foray into research should be under the watchful eye of an experienced senior investigator in a thoroughly conceived project with established methods.

\section{OBSTACLES}

Now for my view of some of the major obstacles impeding training. Our expectations for career development are high. In 3 short years, we want someone to be transformed from a pediatric resident into a triple threat, i.e. the consummate clinician, the innovative investigator, and the captivating teacher. We also ask for superwoman or superman-the person who can juggle three academic tasks and family responsibilities (while leaping tall academic hurdles).
So, my first point to address regarding obstacles is whether this expectation to complete clinical and research training and attain independence is reasonable or even possible in the usual span of 3 years of postdoctoral fellowship. My answer is "no." Contrast this with expectations placed on Ph.D.s, who do not finish their research training in this span of time and obviously do not have the additional load of clinical training. Typically, a Ph.D. scientist will have at least 4 to 6 years of postdoctoral training after an equivalent period obtaining a doctorate. Model programs such as the Pediatric Scientist Development Program, which was conceived by members of our Societies, provide at least 2 years of research education unencumbered by clinical responsibility. Other programs such as the Howard Hughes fellowships give even more time. And many of these programs anticipate that the fellow will apply for additional support to sustain his or her education before attempting to emerge as independent.

It seems to me that two factors have posed major barriers to the accordance of sufficient time for development. The first should be a relatively minor hurdle, but it seems to shape our viewpoint and program planning immutably. We have, as a group, established subspecialty board requirements that are 3 years in most areas. We have then presumed that board eligibility 
TEACHING SKILLS
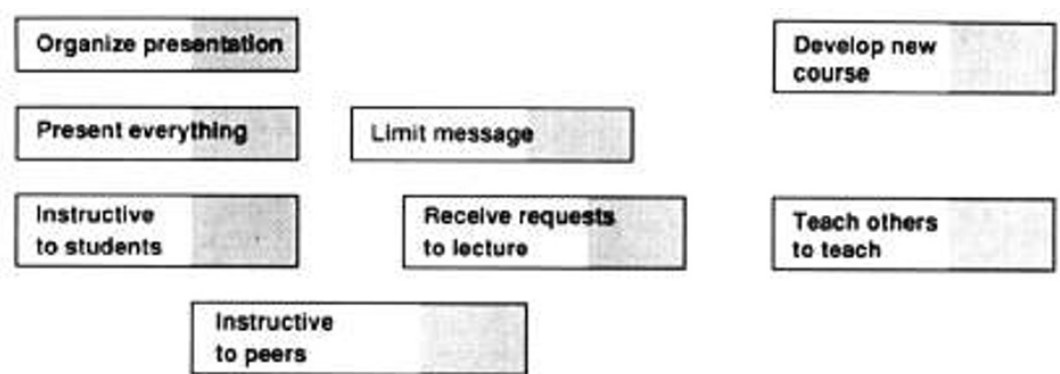

to peers
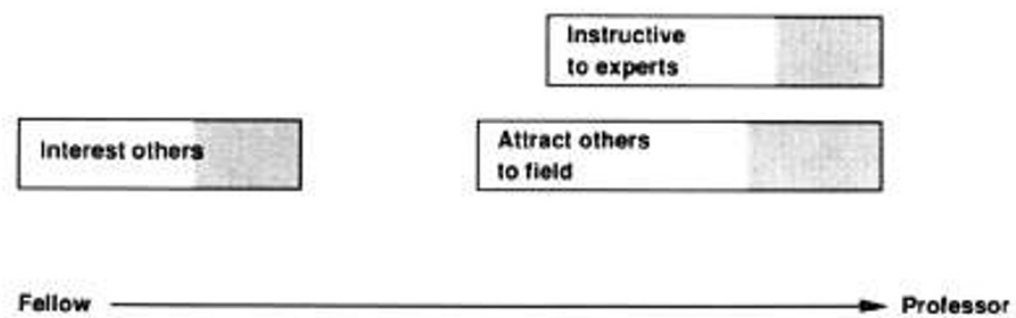

Fig. 3. Refinement of teaching skills during the development from postdoctoral fellow to professor.

\section{WRITING SKILLS}

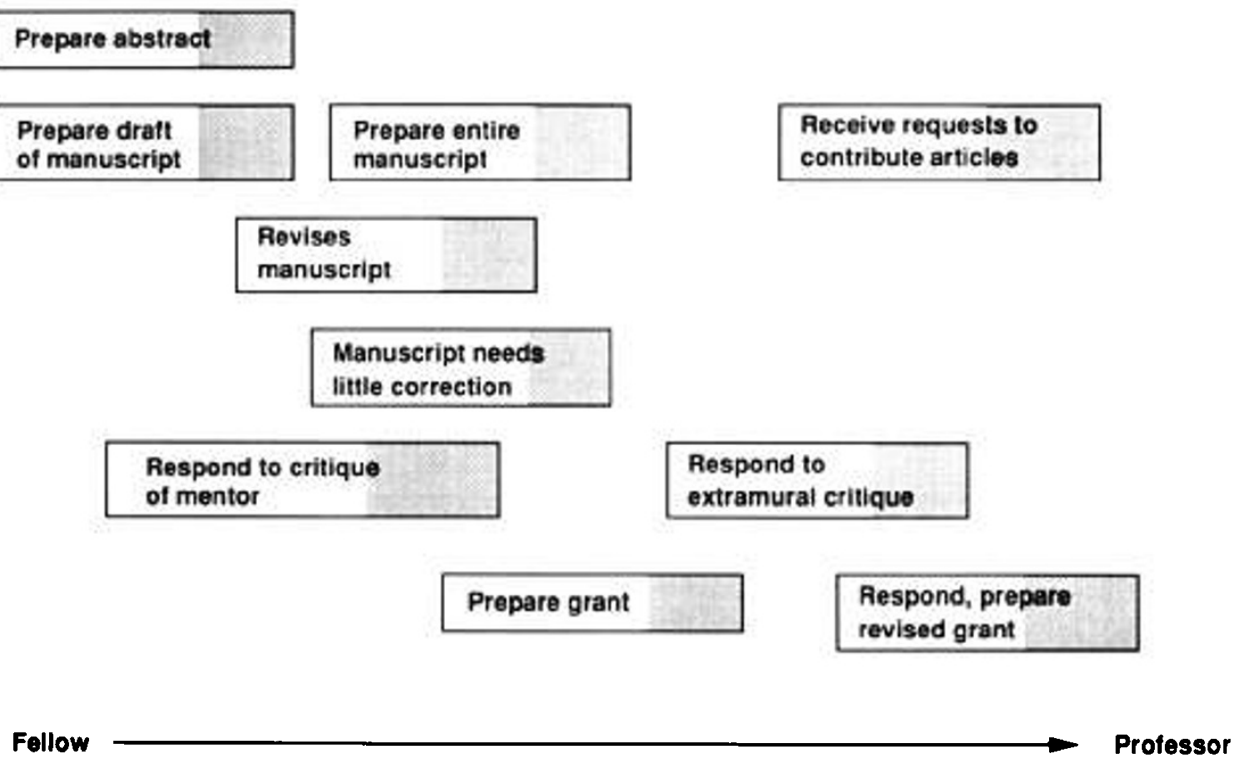

Fig. 4. Refinement of writing skills during the development from postdoctoral fellow to professor.

is tantamount to independence. Surely, this is not the intent of the certification process, but it certainly has become an untoward expectation. Furthermore, this false perception is reinforced by the presence of a research requirement that becomes incorrectly equated with research competence. There is a benefit for the trainee to be exposed to the rigors of research during this stage of development. This may be the first such exposure and the opportunity to embrace research. It should provide the chance to learn how to take an unexplained observation and transform it into a hypothesis that can be tested. This will most certainly improve the acumen of a clinician. For the physician who does not find research stimulating, this serves as the opportunity to close that door without regret or guilt. But it is unreasonable to assume that most, if any, individuals can progress from resident to independent investigator during this time.

The second barrier is far more imposing and it involves a word that seems out of place, but is certainly not out of our consciousness-stipend or salary. To illustrate, $I$ have plotted the stipends for postgraduate training and junior faculty in pediatrics (Fig. 1). I have shown the typical progression through the protected period of postdoctoral training to junior faculty level. I assumed that one might remain for 3 years in pediatric residency before entering fellowship. The data represent average stipends for residents (3) and stipends for National Institutes of Health training grants for the subsequent 3 postgraduate years. I chose average faculty stipends for pediatrics and for two of the more lucrative subspecialties using only base compensation, so I may have underestimated the jump to faculty level (4). What is distressing is not that junior faculty are overpaid, it is that no one, particularly our debt-laden trainees, can resist the urge and need for a more substantial salary. This need can easily overwhelm even the most devoted young investigators and force them to leave the protection of training too early. 

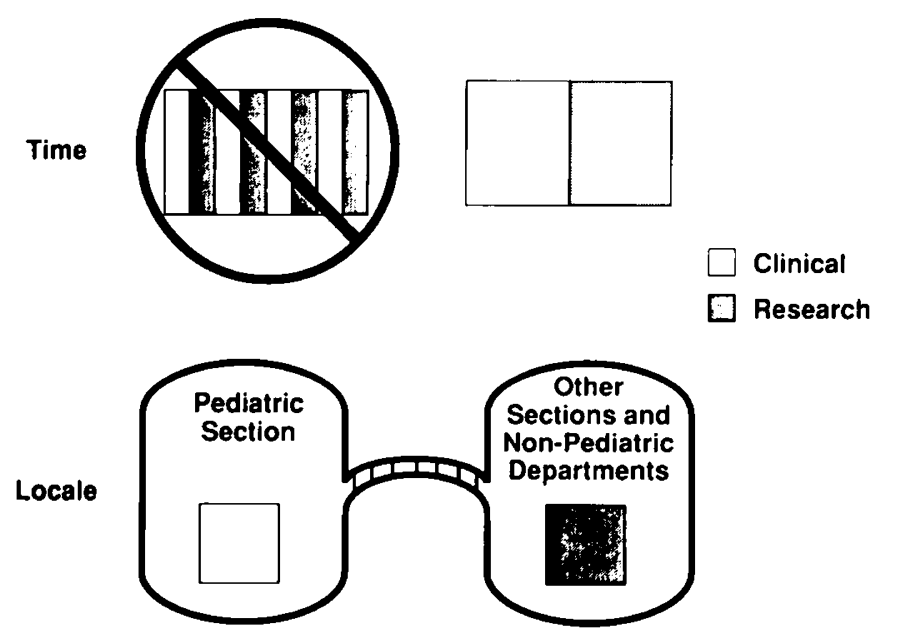

Fig. 5. Allotment of educational endeavors. Time allotment should be in large blocks rather than alternating between clinical and research activities on a monthly basis. Research opportunities may be sought in areas outside the realm of the clinical section through bridges to other sections of pediatrics or in other departments.

The other major obstacle is the strong potential for conflict when acquiring both research and clinical education simultaneously. The demands of each area can clearly interfere with devotion to the other. It is virtually impossible to cease clinical activities abruptly, nor should we encourage trainees to become adept at shedding clinical responsibility in the middle of a commitment. Similarly, one cannot leave a research study on the spur of the moment; this is costly, and the request to drop a project abruptly conveys the wrong message about the nature of research. When there are frustrations, we are likely to gravitate to the realm in which we are most comfortable, and invariably that is the clinical arena, where we receive short-term gratification. Therefore, the opportunity for research training is easily contaminated and education invariably suffers.

I also believe that clinical training is not necessarily accorded its proper protection. This problem is more common and insidious than freely admitted and is exemplified by the frequency with which fellows are asked to assume the role of an attending physician-in my opinion, before their education warrants it and contrary to the spirit of training. Let me give you an example or two. These are excerpts from some letters I have received when reviewing candidates for faculty positions-not necessarily for my own section: "while working in the ... Department, our fellows function much of the time as attending physicians": "In the ... Department we use our fellows as attendings"; and so on...

This is an unacceptable posture for training programs and one that is not restricted to my area of critical care medicine. No doubt there are many who disagree with my analysis and insist that independent responsibility is the only way to learn. I would not argue with the merits of independent thought, but the supervisor should be within range to provide observation and criticism; otherwise, there is no training.

\section{SIGNPOSTS (PERSPECTIVE AND GUIDANCE)}

Now that I have identified some obstacles to education, we can consider how to help the student or fellow attain training goals despite the hurdles. To aim correctly at the goal, the fellow must have perspective to know where he or she stands. The fellow also needs expert critical input and guidance to judge direction and progress. We must be willing to evaluate our own progress, and we cannot flourish without the assistance of others. First, however, I place a large burden of evaluation on the trainee. It is too important a responsibility to delegate entirely to others. To assist some of you in the judgment of your academic development. I propose simple scales to use for reflection. Here are some examples of areas integral to our education. I have separated the abilities and achievements into categories just as has been done with behavioral development using the Denver Scales. We are goal-oriented beasts and are greatly aided by signposts as we wander on our training journey.

The first, and perhaps most obvious, area is the refinement of clinical skills (Fig. 2). I will not go through the details of each scale, but rather highlight some of the points on this and subsequent slides. Our expectation is that a fellow will be transformed into an attending physician. What marks this development? Initially, the fellow is expected to have familiarity with standard texts in the field and will usually broaden the differential diagnosis. We next ask the fellow to evaluate and propose a management strategy for a patient as a consultant. Later, we expect critical knowledge of the basic and clinical research that governs diagnosis and treatment. We then anticipate that the fellow will narrow the focus of the differential diagnosis by carefully weighing the options rather than listing them. The fellow should be able to present information that is informative-initially to students, eventually to other members of the staff. This latter feature reflects the capacity to extend past what is at the surface of the subspecialty; it is the beginning of developing expertise and becoming a unique member of the section, department, and, hopefully, the subspecialty.

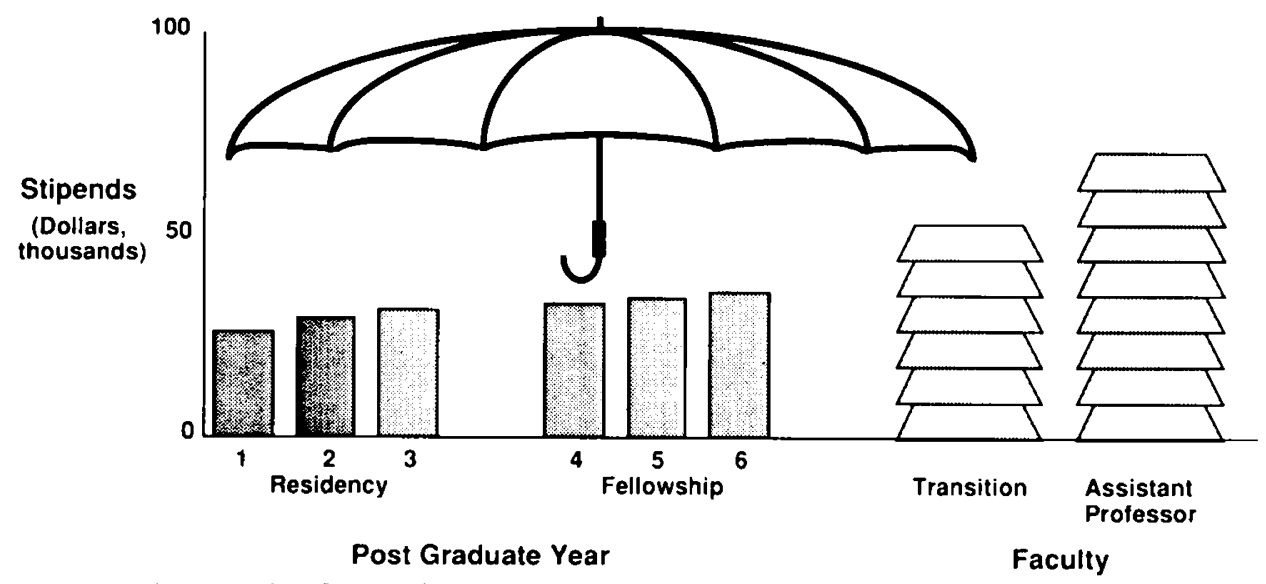

Fig. 6. Stipends for a suggested progression from residency to assistant professor. Data are from same sources as in Figure 1. Here, a period of transition is suggested for further development of skills and knowledge during which there is additional protection from the usual clinical and teaching responsibilities of faculty. 
Another area to consider is the development of teaching skills (Fig. 3). We should not accept that cognitive capacity necessarily confers the ability to teach or communicate. Lectures take practice and organization as well as knowledge of the subject. Initially, the teacher will tell everything known about the subject-the assistant professor syndrome. With experience, there should be focus and limitation of the message. The reality that only a few points can be made will become painfully apparent. We should also expect the teacher to interest the audience in the field. An excellent teacher will actually attract others to the field and be instructive to experts.

A fellow must develop skills in writing and be able to prepare an abstract and a draft of a manuscript (Fig. 4). The fellow must respond to the critique of others. This ability to assimilate and sort criticism is crucial. The trainee must learn to prepare a grant and write a critique of others' work. These tasks seem obvious because we weigh advancement by the capacity to have manuscripts published and grants accepted. However, how often have we read manuscripts for review and put them down because the text was tedious, confusing, and poorly written? This becomes a major obstacle for acceptance, and none of us would like to have our articles rejected for such a reason. Moreover, it takes time and effort to trim and shape so that what is written is clear. Pascal's apology - "I have made this letter longer than usual because I lack the time to make it shorter" (Blaise Pascal, Provincial Letters, XVI, 1657)-is a most apt reminder that the weight of a manuscript is not a function of its length. We need to devote the time during training to refine this skill as was proposed by the late Julius Comroe, who developed a sophisticated postgraduate course to teach scientific writing.

There are also motor skills we expect to mature that vary widely among areas. A fellow should initially be able to follow a protocol or an experiment with direct supervision. Later, we expect that the protocol can be completed when the mentor is home, out of town, or even on sabbatical.

In addition to self-assessment, the other essential ingredients for critical review come from the training milieu. In large part, we choose programs based on the environment and the mentors. We surround ourselves with those whose qualities we emulate and behavioral patterns we mimic. These pivotal individuals, whether they be peers or teachers, provide security, support, and vital input to our career. Accordingly, we must welcome and demand the expertise and criticism from them. This will be our best means for obtaining perspective on our progress, validity to our ideas, and guidance for righting our course when we are astray. We should expect that our manuscripts will be read critically and dissected before they are sent to outside reviewers and that our presentations will be reviewed well in advance of a talk. We, as faculty, should not just send fellows to give lectures we do not wish to deliver. Rather, we must devote the time and effort to listen to and critique their presentations-and not the day before when it is too late to make substantive changes and too costly or too much trouble to alter the slides.

In addition to the critical environment, there is a special relationship that develops between mentor and student, steeped in parallels with that between parent and child. As during childhood, there is a transition from dependent to independent being.

Those of you who serve as mentors know the incredible responsibility of that role. Recall that Mentor was the man to whom Odysseus entrusted his son. Telemachus, before taking off on his own journey. Athena, the goddess of wisdom, actually assumed the disguise of Mentor to act as advisor to the young Telemachus.

Well, none of us hold such stature, but in this spirit we must devote extraordinary time, effort, and attention to provide mentorship and criticism. There must be the willingness to stand two steps back while watching someone struggle with a problem or technique that you can master, and the capacity to separate when the time is ripe. At some point, the student must break free from the safety net. We must all learn whether we can develop a hypothesis on our own, whether we can complete a study and write a manuscript without the watchful eye of the mentor.

\section{SUGGESTIONS}

With many of these concerns in mind, are there any substantive suggestions that I can provide? Let us return first to some of the obstacles I identified earlier.

My first suggestion is to the students, residents, and fellows: give yourself enough time for initiating your education in academic pediatrics. Take advantage of such programs as the Society for Pediatric Research Summer Student Research Program, the Howard Hughes fellowships, and the Pediatric Scientist Development Program, to name a few, which will give you unencumbered time to taste research and the chance to attack some windmills even though there are some obvious risks. Accept the luxury of this protected time. Consider taking a year early in your medical career for such a venture.

For the clinical component of the training. I turn to my colleagues who are faculty and ask. "Are you as a faculty member willing to be on call without a fellow?" "Is the schedule always devised to have coverage by the fellow so that you are protected from front line duties?" "How many times have you pulled a fellow from research-related activities to cover the clinical service?" I have heard it said, and I agree, that the best training environment is one that does not need fellows.

My next suggestion is that we insist on large blocks of time for educational endeavor (Fig. 5). Alternating clinical and research months rarely is a reasonable solution. Shuttling from one realm to another wastes much time for transition. The distractions are many and the trainee is ill equipped to filter them. The restrictions placed in many of the special training programs recommending that trainees spend their time in another department are for good reason. We should make every effort to incorporate research opportunities and establish alliances with other sections and departments, especially basic departments. Such cross-fertilization is particularly important for subspecialties without wellestablished research bases; critical care and emergency medicine represent two such examples. Not every subspecialty section may have the capacity to train fellows. We will be far better off if we can limit the proliferation of subspecialty programs and foster much stronger disciplines. As stated 10 years ago by Dr. Petersdorf, "We need to train fewer people to do research but we need to train them longer and better" (5).

Next, we, as faculty, must grant our trainees sufficient time for development. We should erase the notion that 3 years is sufficient to establish clinical and research independence. We must insist on institutional mechanisms to foster protection and guidance for our academic progeny. We should invest heavily in our most promising fellows and students. This investment might be in the form of extended fellowships or transitional appointments, e.g. instructor or research associate with less than full faculty responsibility (Fig. 6). I would suggest that an increased stipend, but continued protection and mentoring, is essential. I see no means of providing time for nurturing many of the trainees without such transition. This transition period should be viewed not as a penalty for slow learners but rather as a bonus for the talented.

It is also worth recognizing that career development, just like other facets of human development, does not necessarily proceed in a coordinated fashion. It is unwise to link proficiency in clinical practice with that in research. We should accommodate those talented fellows who have matured in one sphere but need further progress in other areas.

We could consider other creative options such as assistance with payment of interest on student loans during this transition period. Median debt of fourth-year medical students is in the range of $\$ 40000-60000$ (\$40 000 for public school graduates, $\$ 60000$ for private school graduates) (6). We cannot expect the former law students with large school debts who work in our 
congressional offices to create options and have a great deal of sympathy for former medical students with similar debts. Rather, we must look to internal solutions. The interest (approximately $\$ 6000$ ) would not be a formidable expense for a section but would help considerably with the burden after fellowship and would convey a sense of investment in an individual.

Finally, how can we foster independence when it is appropriate? We must be willing to let go of proprietary rights to our trainees and give space for new ideas to be generated. We need to permit a manuscript to be published without our name on it. If this is not acceptable, we might return to the proposal put forth by Drs. Davis (0.92) and Gregerman (0.08), in an article in the New England Journal of Medicine entitled "Parse Analysis" (7). They suggested that we bestow proper credit according to contribution as shown here by the fractions in parentheses by each author's name. The only time these fractions do not total 1.0 is when the work is incomplete or includes an investigator who was on sabbatical when the manuscript was submitted. One test of a mentor is the ability to remain nameless and promote junior faculty. In the end, we should view the success of our progeny as our own success rather than stifle it. I hope we can all accept this challenge.

In summary, I am excited and hope you are by the wealth of opportunity for the pediatrician interested in an academic career. I look forward to going to work, and even in the physically taxing field of critical care, I do not feel bored, exhausted, or, in current parlance, "burned out."

Much of the burden of education falls on the student, which we all remain throughout our careers. You must decide where you want to go-your first goal. In close conjunction with a mentor, you need to decide by what route you will get there. Accept that there will be many obstacles on the road, so slow down and do not rush. Separation from your mentor is abrupt, but must be timely, so that you are prepared to assume independence as you enter academia.

Acknowledgments. I thank the many individuals who have helped me formulate my thoughts and develop this manuscript. In particular, I would like to acknowledge the critical review from Drs. J. Julio Pérez Fontán, Norman J. Siegel, and Joseph B. Warshaw, and my wife, Sandra S. Lister; the helpful criticism and assistance with preparation of the figures and manuscript from Lisa DeLizio and William Aquila; and the invaluable input from my many mentors including Julius $\mathrm{H}$. Comroe, Julien I. E. Hoffman, Michael A. Heymann, Abraham M. Rudolph, and Norman S. Talner.

\section{REFERENCES}

1. Warshaw JB: SPR Presidential address: micro- and macro-environments in academic pediatrics. Pediatr Res 16:911-916, 1982

2. Kelch RP Novello AC: Training pediatric scientists. Pediatr Res 25:1-5, 1989

3. Council of Teaching Hospitals: Survey of Housestaff Stipends, Benefits and Funding. 1992. Association of American Medical Colleges, Washington. DC, October 1992

4. Report on Medical School Faculty Salaries 1992-93. Association of American Medical Colleges, Washington. DC. March 1993. p 11

5. Petersdorf RG 1983 Sounding board. Is the establishment defensible? N Eng] J Med 309:1053-1057

6. American Medical Education: Institutions. Programs and Issues. Association of American Medical Colleges. Washington. DC. November 1992

7. Davis PJ, Gregerman RI: Parse analysis: a new method for the evaluation of investigators' bibliographies. N Engl J Med 281:989-990, 1969 